\title{
Consumo de (i)mobilidades e discurso: a cultura da mobilidade na publicidade das marcas ${ }^{1}$ \\ Consumption of $(\mathrm{im})$ mobilities and discourse: the culture of mobility in brand advertising
}

Maria Alice de Faria Nogueira ${ }^{2}$

Resumo Este artigo tem como objetivo apresentar os resultados da pesquisa de doutorado da autora que investigou a cultura da mobilidade (URRY, 2003) a partir de seus discursos e suas representações, com especial interesse na comunicação publicitária global. A hipótese de que há um consumo de (i)mobilidade sendo feito quando o indivíduo sai em busca de objetos que suportem sua (i)mobilidade cotidiana com certa estabilidade e menor risco foi validada, a partir da interpretação do discurso publicitário de marcas globais veiculado no Brasil em três momentos distintos: junho de 1982, junho de 1998 e junho de 2014, durante o período da Copa do Mundo Fifa. A metodologia da pesquisa foi baseada na hermenêtica de profundidade (THOMPSON, 2000) e considerou as articulações entre texto e contexto na análise formal de 40 anúncios impressos.

Palavras-chave: Mobilidade em potência; Discurso publicitário; Publicidade global; Hermenêutica de profundidade; Copa do Mundo Fifa

\footnotetext{
Abstract This article presents the results of my PhD thesis, which investigated the idea of mobile culture (URRY, 2003) based on its discourses and representations, with special focus on global advertising communication. The hypothesis that consumption of (im)mobility exists when individuals seek objects that support their everyday (im) mobility with a certain stability and less risk was validated, by interpretation of the advertising discourse of global brands disseminated in

${ }^{1}$ Versão preliminar deste trabalho foi apresentada no VI Pró-Pesq PP - Encontro de Pesquisadores em Publicidade e Propaganda. CRP/ECA/USP, 27 a 29 maio 2015.

2 Universidade Federal do Rio de Janeiro - UFRJ, Rio de Janeiro, RJ, Brasil.

E-mail: prof.maria.alice@gmail.com.
} 
Brazil at three different moments: June 1982, June 1998 and June 2014, when Brazil participated in the FIFA World Cup in Spain, in France and in Brazil, respectively. The research methodology was based on depth hermeneutics (THOMPSON, 2000) and considered the articulation between text and context in the formal analysis of 40 printed advertisements selected for investigation.

Keywords: Motility; Advertising discourse; Global advertising; Depth hermeneutics; Fifa World Cup 


\section{Introdução: sobre a tese ${ }^{3}$}

No mundo, hoje, tudo está em movimento. Pessoas, objetos, valores, informação e imagens circulam cada dia mais intensa e extensamente em um ambiente social fluido, em rede e de riscos. Quando a mobilidade torna-se parte importante da experiência cotidiana e os deslocamentos físicos, geográficos, virtuais ou imaginativos tomam a frente nas relações e alteram radicalmente os modos de vida em todas as esferas - social, cultural, política e econômica -, nesse momento uma cultura da mobilidade (URRY, 2003) se impõe e envolve a todos em novas possibilidades e experiências, assim como, em novos constrangimentos, riscos e discursos que devem ser estudados.

O cada dia mais intenso imbricamento entre cultura da mobilidade e discurso publicitário em um ambiente comercial e de negócios, em grande medida, globalizado constituiu a base que sustentou a pesquisa de tese e que delineou as duas premissas fundamentais do estudo:

- A primeira, de que as coisas do mundo chegam até o sujeito apesar de sua imobilidade, isto é, por meio dos objetos, das informações e das imagens que circulam globalmente. Neste sentido, nas sociedades contemporâneas, o fenômeno da mobilidade ganha novos contornos e se manifesta não só pelo deslocamento físico, mas também pode ser experimentado de forma virtual ou imaginativa;

- A segunda, de que, a despeito de seu caráter comercial, persuasivo e de vendas, a publicidade também pode ser encarada como um bem cultural no duplo sentido do termo: como produto e como produtora da cultura que a envolve e da qual faz parte quando seu discurso se apropria e/ou é apropriado pela fala dos indivíduos no seu cotidiano.

E foi exatamente esta identificação do fenômeno social da mobilidade, i.e., o movimento positivamente valorado, com o discurso da publicidade que a tese trouxe à luz como tema de pesquisa e debate.

${ }^{3}$ NOGUEIRA, M. A. de F. Mobilidade em potência e discurso publicitário na sociedade contemporânea globalizada. Tese de Doutorado em História, Política e Bens Culturais. Centro de Documentação da História Contemporânea do Brasil, FGV-RJ. Março, 2015. 329p. Disponível em: http://hdl.handle.net/10438/13704. 
Neste sentido, a tese buscou investigar a cultura da mobilidade a partir de seus discursos e suas representações, com especial interesse na comunicação publicitária global. Ao consideramos que todos os objetos fazem parte dos sistemas lógicos da mobilidade e que carregaram, em si, o potencial do movimento que tornará a vida do sujeito mais ou menos (i)móvel, em função de suas escolhas, estilo e projetos de vida, a tese levantou a hipótese de que há um consumo de (i)mobilidade sendo feito quando o indivíduo sai em busca de objetos que, a partir de sua disponibilidade (ready-to-handedness) e potencial de uso em relação às condições dadas pelo ambiente (affordance), suportem sua (i)mobilidade cotidiana com certa estabilidade e menor risco.

Para validar a hipótese, a investigação verificou se, e de que maneira, a cultura da mobilidade, a motilidade (como atributo dos bens) e a parceria entre os indivíduos e os objetos (híbridos) foram discursivamente representadas pela publicidade das marcas, dos produtos e dos serviços globais independentemente do tipo de benefício e/ou da categoria comercial do bem a ser divulgado.

As peças foram analisadas segundo o enfoque da hermenêutica de profundidade, cujo principal fundamento é a compreensão de que a interpretação de qualquer forma simbólica só é possível, nos termos de Thompson (2000), a partir da articulação de seu texto com o contexto no interior do qual houve sua produção, veiculação e recepção. Levando em conta a interpretação do cotidiano e da experiência de vida no mundo social contemporâneo - por meio de autores relacionados às áreas de História, Sociologia, Antropologia, Economia, Ciência Política, Relações Internacionais e Comunicação Social -, a investigação foi feita em três diferentes fases que compõem a hermenêutica de profundidade: a análise sócio-histórica; a análise formal; e a interpretação das formas simbólicas.

Tecnicamente, para a análise formal dos anúncios, foram consideradas as duas categorias de análise - mobilidade física ou geográfica e mobilidade virtual ou imaginativa - que serviram como ponto de partida para a interpretação das formas simbólicas, que foi feita com base em 
uma análise comparada dos discursos da comunicação publicitária das marcas globais.

Como corpus de análise, foram utilizadas 40 peças impressas: 14 de 1982, 12 de 1998 e 14 de 2014. Deste total, 14 anúncios são de nove anunciantes nacionais e 27 anúncios são de 22 anunciantes globais; 19 anúncios são de marcas, produtos ou serviços relacionados à mobilidade física e geográfica e 21 são relacionados à mobilidade virtual ou imaginativa.

Como referência para a busca e seleção dos anúncios, foi utilizado um evento esportivo que, ao longo de sua história, tornou-se um poderoso meio através do qual as marcas e seus produtos são globalmente divulgados: a Copa do Mundo Fifa de futebol. Megaeventos como a Copa do Mundo são hubs socioespaço-temporais que mudam e reorganizam os fluxos globais de pessoas, visto que possuem apelo para serem vistos "ao vivo"; e que também são geradores de robustos fluxos globais de mercadorias, de informação e de imagens.

Como o locus da investigação foi o Brasil, foram selecionados anúncios de marcas veiculados no país durante o período de três Copas do Mundo Fifa: junho de 1982, na Espanha; junho de 1998, na França; e junho de 2014, no Brasil, que cobrem o período proposto pela pesquisa.

A principal mídia impressa que serviu como fonte de investigação foi a revista Veja4. Editada pela Abril desde 1968, já na década de 1980, Veja era a revista semanal de circulação nacional com a maior tiragem do mercado. Hoje, vende uma média de 1,1 milhão de exemplares, entre as assinaturas e vendas em bancas de jornal. Pela sua história editorial, circulação nacional e expressão como mídia durante as três décadas de investigação, Veja nos permitiu fazer uma análise comparada entre a publicidade das marcas em 1982, 1998 e 2014.

Baseada no entendimento de que a interpretação de um texto só é possível se há a compreensão mínima do contexto no qual o objeto de análise foi criado, veiculado e recepcionado, o primeiro capítulo da tese

4 Todos os anúncios citados neste artigo foram selecionados nas edições da revista Veja de junho de 1982, junho de 1998 e junho de 2014. Disponível em: http://veja.abril.com.br/acervodigital/ home.aspx. 
foi sobre a perspectiva metodológica da hermenêutica de profundidade. A partir desta apresentação inicial, o trabalho foi dividido em quatro capítulos que seguiram a proposta do referencial metodológico: cada capítulo focou em um período da investigação (1982, 1998 e 2014) e, a partir dali, trabalhou com as questões da cultura da mobilidade e do discurso da publicidade, à luz de um contexto histórico e midiático. Em cada capítulo, foram apresentados dois estágios do enfoque da hermenêutica: a análise contextual e a análise formal, com base nos anúncios selecionados de cada período. Por fim, no capítulo final, a última fase do enfoque da hermenêutica em profundidade - a interpretação das formas simbólicas - foi tratada, por meio da análise comparada entre os períodos selecionados para a investigação.

A seguir será apresentado um resumo destes resultados, cujo ponto fundamental foi a interpretação dos discursos das marcas globais a partir do cenário sócio-histórico de fundo.

\section{Entre o local e o global: perspectiva teórica e análise sócio-histórica}

No intervalo de 32 anos (1982-2014), período sobre o qual a investigação se debruça, o Brasil teve oito presidentes da República: a começar pelo último governante do regime militar, um que morreu antes de assumir, outro que saiu antes de seu impeachment, dois que foram presidentes porque eram vice e três reeleitos: um sociólogo, um operário e uma mulher (a primeira a assumir o cargo), ex-guerrilheira que lutou contra o regime do primeiro presidente da lista.

Também durante este período, o governo lançou sete planos econômicos e houve quatro trocas de moeda. Parte desses planos foi implementada na década de 1980 e o insucesso das medidas fez com que esses anos ficassem conhecidos, no que diz respeito à economia, como a "década perdida". Mas o mesmo não se pode falar com relação à política: com a redemocratização, houve a emergência de uma nova sociedade civil e o crescimento de novas instâncias de representação, como sindicatos e partidos. 
No meio destas três décadas, nos anos 1990, o dólar chegou a valer $\mathrm{R} \$ 4$ e o real chegou a valer mais que o dólar ${ }^{5}$. A inflação caiu de $2.477 \%$ ao ano (a mais alta registrada no país) ${ }^{6}$ em 1993 para 6,75\% em 2014. De 2003 a 2009, aproximadamente 20 milhões de brasileiros saíram da pobreza e ascenderam à (nova) classe $\mathrm{C}$, com incrementos na renda $\mathrm{e}$ no potencial de consumo (NERI, 2010, 2012).

A abertura do mercado brasileiro a empresas globais, em detrimento do mercado fechado com foco no nacional-desenvolvimentismo característico do período militar, em conjunto com as melhorias na economia e a estabilização da moeda na década de 1990, posicionou o Brasil como um importante local de investimento. Principalmente a partir dos anos 2000, o Brasil entrou no mapa global de comércio e de consumo e tornou-se um dos protagonistas das novas economias emergentes, os BRICS (VISENTINI, 2013).

Foram duas Copas do Mundo de futebol ganhas, em 1994 e 2002, fazendo do Brasil o único pentacampeão da história do torneio. Neste período, também, o Brasil sediou uma Copa do Mundo, na qual foi derrotado nas semifinais pelo inédito placar de 7 x 1 .

E em 1984, milhares de pessoas saíram às ruas pelas eleições diretas para presidente a República; em 1992, milhões de brasileiros, principalmente jovens, foram para as ruas pelo impeachment do presidente Fernando Collor de Mello. Em 2013, em um movimento que ficou conhecido como "Jornadas de Junho", uma sociedade civil jovem, mas desencantada com seus representantes e sem perspectiva quanto ao seu projeto de vida (WERNECK VIANNA, 2014) ${ }^{8}$, participou de manifestações em todo o país em protesto pela falta de investimentos em saúde, educação e mobilidade urbana, entre outros temas sociais, diante de

\footnotetext{
${ }^{5}$ Disponível em: http://veja.abril.com.br/especiais/veja_40anos/p_170.html. Acessado em: 19 jan. 2015.

${ }^{6}$ Disponível em: http://veja.abril.com.br/especiais/veja_40anos/p_l70.html. Acessado em: 19 jan. 2015.

7 Disponível em: http://agenciabrasil.ebc.com.br/economia/noticia/2014-10/inflacao-acumuladaem-12-meses-e-maior-em-tres-anos. Acessado em: 19 jan. 2015.

${ }^{8}$ Disponível em: http://www.ihu.unisinos.br/entrevistas/521147-a-busca-por-reconhecimento-eparticipacao-politica-o-combustivel-das-manifestacoes-entrevista-especial-com-werneck-vianna-. Acessado em: 19 jan. 2015.
} 
altos gastos com infraestrutura da Copa do Mundo Fifa 20149. Alguns autores (MAIA e ROCHA, 2014, entre outros) posicionaram as Jornadas de Junho como um dos movimentos sociais que fizeram parte de um movimento maior, globalizado, que, em última instância, considerando caso a caso, questionava, ou mesmo apontava para, uma crise e a falência do modelo do capitalismo global.

Em resumo: em 30 anos, o Brasil saiu de uma situação singular - o fim do regime ditatorial militar - e das condições políticas, econômicas e sociais dela advindas, para certo alinhamento político, econômico e social global.

Permeando toda esta história há, como pano de fundo, especialmente nos países desenvolvidos do hemisfério Norte, o crescente desenvolvimento tecnológico de uma rede de sistemas complexos e interdependentes nas áreas de comunicação e de transporte, que suportam a - cada dia mais - intensa e extensa circulação de pessoas, de coisas, de imagens e de informação. A globalização, neste caso, se apresenta como a outra face da emergência de uma cultura da mobilidade e ambas, em conjunto, elevam o movimento, a circulação e o potencial de deslocamento das pessoas, das coisas, das informações e de imagens à condição fundamental para a experiência de vida cotidiana, permanentemente on the move.

A exacerbação das práticas da mobilidade e a globalização dos mercados acabam por enfraquecer as fronteiras do nacional nos seus diversos aspectos políticos, econômicos e sociais e, em consequência, o indivíduo desponta como a principal instância de legitimação social em um ambiente fluido, em rede e de riscos (KESSELRING, 2008; BECK, 2008, entre outros). Para organizar a vida à distância e em constante movimento, o indivíduo vai à busca de referências sociais e núcleos de estabilidade, dos quais os objetos são parte constitutiva importante, que sustentem sua permanente (i)mobilidade. A parceria entre o homem e a máquina, denominada como "híbridos" (URRY, 2007), empodera o

\footnotetext{
9 Disponível em: http://esportes.estadao.com.br/noticias/futebol,protestos-arruinam-imagem-do-brasil-e-preocupam-a-fifa,1045721. Acessado em: 19 jan. 2015.
} 
sujeito ao apoiá-lo e ao oferecer o potencial de movimento necessário para a realização de seus projetos e estilos de vida.

A partir do momento em que a mobilidade é considerada menos pelos sistemas ou pela tecnologia dos meios e mais pelas pessoas, seus ritmos e condições espaço-temporais individuais, há um deslocamento no foco das análises sobre a cultura da mobilidade, suas novas possibilidades e experiências, assim como seus constrangimentos, riscos e discursos, do que seria o movimento real, mesmo que virtual, para a mobilidade em potência, isto é, motilidade, suas possibilidades de acesso, habilidades e de apropriação (KAUFMANN, 2002). Esta "migração" do foco das análises fortalece a noção de que os estilos e projetos de vida, atualmente, são (re)construídos e vivenciados grande parte à distância, com base nesta relação entre as pessoas e os objetos, traduzida nos híbridos e na sua vida $h a n d y$.

Neste sentido, para além do tipo de mobilidade vivenciada - corporeal travel, virtual travel, imaginative travel ou communicative travel (URRY, 2007) -, há os estilos e projetos de vida do indivíduo - sedentary, re-embbeded, incursive ou cosmopolitan (KAUFMANN e MONTULET, 2008) -, que vão demandar diferentes usos e consumos de variados objetos que potencialmente servem à (i)mobilidade não só por fazerem parte dos sistemas de mobilidade, mas por carregarem em si o potencial do movimento que vão colocar (ou não) o sujeito em circulação, a princípio, com menor risco.

Ao enfatizar a importância da cultura material (APPADURAI, 1986; MILLER, 2013) na vida dos híbridos, o paradigma das novas mobilidades (URRY, 2007, entre outros autores) coloca em destaque o movimento dos objetos. Causa e consequência da globalização, o incremento na circulação dos objetos alçou o consumo das marcas globais ao patamar das instâncias de representação do indivíduo, transformando objetos e marcas em símbolos da cultura (ORTIZ, 2003) e, até mesmo, de atuação política, como no caso da campanha "Vem pra Rua", da Fiat, nas Jornadas de Junho de 2013 no Brasil. 


\section{A cultura da mobilidade na publicidade das marcas: análise formal e interpretação do discurso}

Desta forma, é possível afirmar que a hipótese de um consumo de (i) mobilidades foi validada, a partir do momento em que ficou clara a presença da cultura da mobilidade no discursos das marcas globais.

A despeito de seu caráter comercial, a publicidade, como atividade que oferece visibilidade ao consumo (ROCHA, 1985; MCCRACKEN, 2003 e 2012) e parte integrante do movimento dos objetos, foi afetada por esta propensão à mobilidade do sujeito contemporâneo não só tecnicamente, mas discursivamente, e passou a traduzir em seu texto, verbal e não verbal, a cultura da mobilidade de pelo menos três maneiras: pelo objeto, pelo meio e pelo próprio discurso.

Em um cenário móvel, em rede e de risco em que o sujeito "parece flutuar livremente" (HALL, 2003), o consumo e suas práticas sociais se apresentam como forma de fixar, mesmo que temporariamente, uma personalidade e uma identidade que prendem o sujeito a um projeto de vida. Num ambiente "solto", não fixo, basicamente de passagem e de circulação de pessoas, bens, dinheiro, ideias, imagens e informação, a sociedade buscou inventar novas instâncias para a integração das pessoas. Há na sociedade contemporânea uma noção de pertencimento que foge às regras modernas de representação social em função de nacionalidade e cultura histórica que, sob discursos forjados pedagogicamente sobre a nação, integravam os sujeitos. Este escape às regras possibilita a construção, pela aquisição, posse e usos dos bens, de novas configurações identitárias que têm no consumo um dos seus pontos de partida (NOGUEIRA, 2010, p. 48).

No entanto, indo um pouco adiante nesta questão, é possível afirmar que na sociedade móvel, em rede e de risco, o consumo ultrapassa sua condição de operador de identidade e emerge como uma prática que suporta certa estabilidade em um mundo em constante movimento.

De acordo com Urry (2007), Appadurai (1986) e Miller (2013), a cultura material empodera o ser humano. Neste sentido, ao adquirir algo, um "treco", nos termos de Miller (2013, cap. 2), os indivíduos 
adquirem a mobilidade em potência necessária para escapar dos riscos da vida em movimento, assim como para vivenciar certa estabilidade no cenário social fluido contemporâneo. É exatamente nesta parceria entre o indivíduo e os "trecos", portanto, nos híbridos, que reside a força: em cada objeto - tangível ou não, mesmo abstrato, como a tecnologia, ou ainda algo constitutivo da natureza, além da própria humanidade - existe certo potencial de uso (affordance) em relação ao ambiente, que está disponível (ready-to-hand) para ser transformado, ou não, em movimento. A motivação para o consumo de bens, nesse sentido, seria a mobilidade em potência, ou motilidade, que será ou não transformada em movimento pelos indivíduos quando, e se necessário for, com base em seus estilos e projetos de vida.

Esta foi a razão fundamental da ideia de um consumo de (i)mobilidades levantado como hipótese da pesquisa de tese em referência. Com o atributo de motilidade em cada objeto, a publicidade eleva o potencial de movimento como seu principal argumento discursivo. Sobre este aspecto, a publicidade não venderia mais só razão prática do uso do bem, como em uma sociedade industrial; ou não mais venderia só identidade ou status conseguidos pela aquisição do bem, como numa sociedade de consumo (BAUDRILLARD, 1970); mas, principalmente, venderia a motilidade, isto é, a mobilidade em potência, necessária para dar conta da vida em uma sociedade móvel, em rede e de riscos, no interior da qual uma cultura da mobilidade se faz o tempo todo presente.

Como veremos nas imagens a seguir, em um primeiro momento, em 1982, a mobilidade estava presente por meio dos objetos e do desenvolvimento tecnológico que proporcionava a circulação globalizada de pessoas, coisas, informações e imagens. Neste sentido, o foco era nos sistemas e os exemplos desta afirmação puderam ser vistos nas peças do Monza $^{10}$, do Itaú Eletrônica Global ${ }^{11}$, da Sharp e, principalmente, do walkman $^{12}$, mas também da Pierre Cardin, que, mesmo não sendo uma marca de produtos de tecnologia como as outras acima citadas, resumiu

10 Anúncio de página dupla veiculado na revista Veja, edição 719, de 16 jun. 1982, p. 68-69.
11 Anúncio de página simples veiculado na revista Veja, edição 718, de 9 jun. 1982, p. 80.
12 Anúncio de página simples veiculado na revista Veja, edição 718, de 9 jun. 1982, p. 163 
muito bem a ideia de movimento ao convocar o público leitor a entrar no seu "universo exclusivo" a partir do apelo visual sinestésico de seu anúncio.

Como citado, os sistemas tecnológicos alteraram o cotidiano ao possibilitar a experiência de vida à distância em diversas e diferentes esferas. Neste anúncio, de 1982, o Itaú já chamava atenção para este fato, inclusive destacando que o uso do sistema pelo cliente daria melhores condições ao banco para oferecer um atendimento "cada vez mais humano” em suas agências. A parceria entre o banco e o cliente já seria, nesta época, o começo de um "proto-híbrido", se assim for possível falar.

Por último, é interessante ressaltar a "localidade" do discurso, tanto textual quanto visual, utilizado pelo anunciante. No caso, o Brasil simboliza o mundo, ao mesmo tempo que a assinatura da peça é feita pelo Itaú Eletrônica Global, sendo esta a única vez, em todos os anúncios de marcas nacionais ou globais, nas seis edições pesquisadas de 1982, que a palavra "global" aparece em um anúncio.

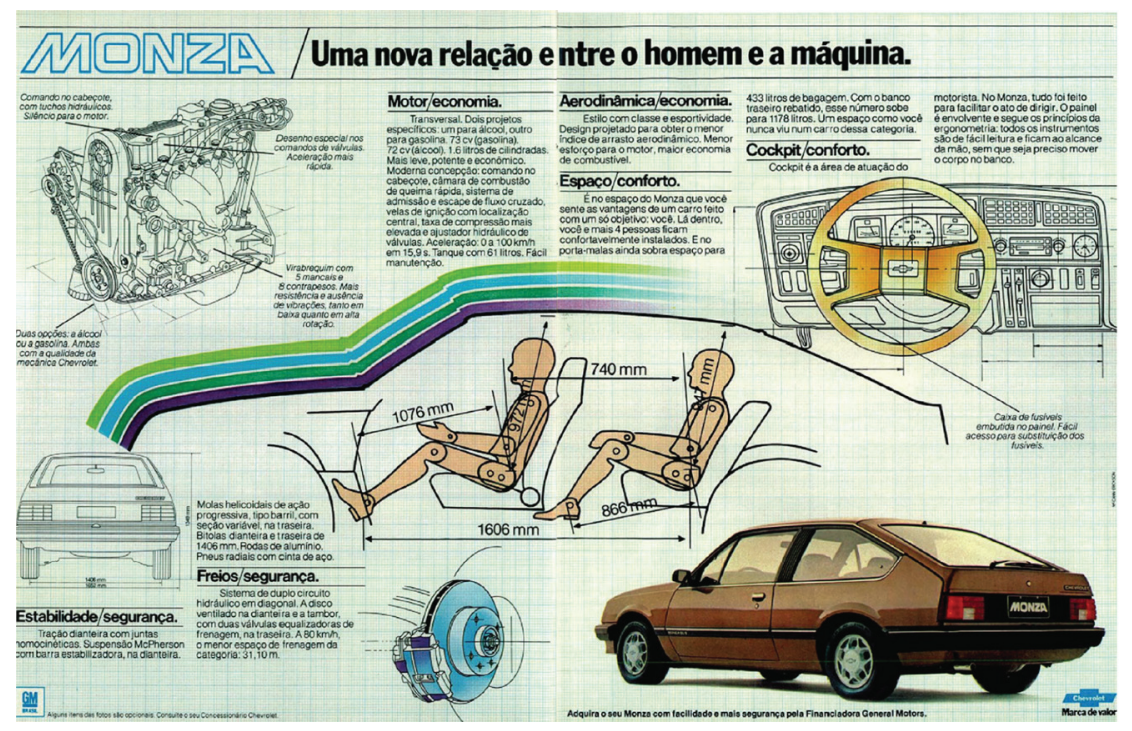

Monza - anúncio página dupla veiculado na revista Veja, ed. 719, de 16 jun. 1982, p. 68-69.

Fonte: http://veja.abril.com.br/acervodigital/home.aspx. 


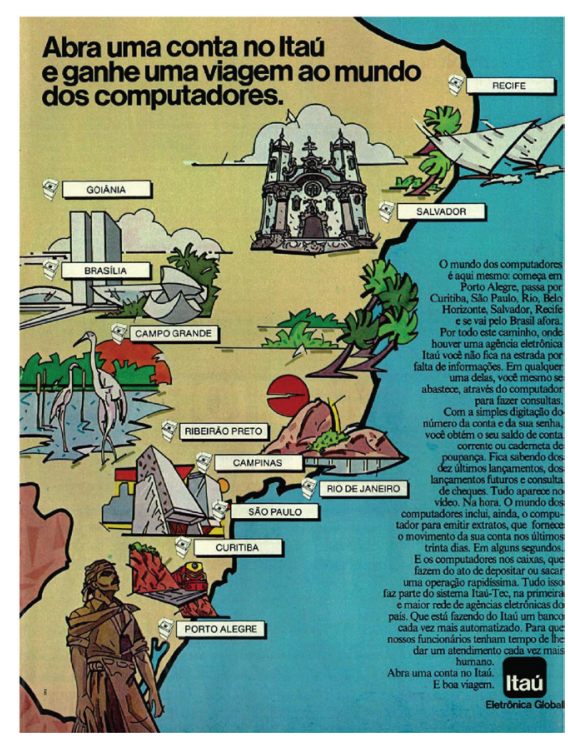

Itaú Eletrônica Global - anúncio página simples veiculado na revista Veja, edição 718, de 9 jun. 1982, p. 80 .

Fonte: http://veja.abril.com.br/acervodigital/ home.aspx.

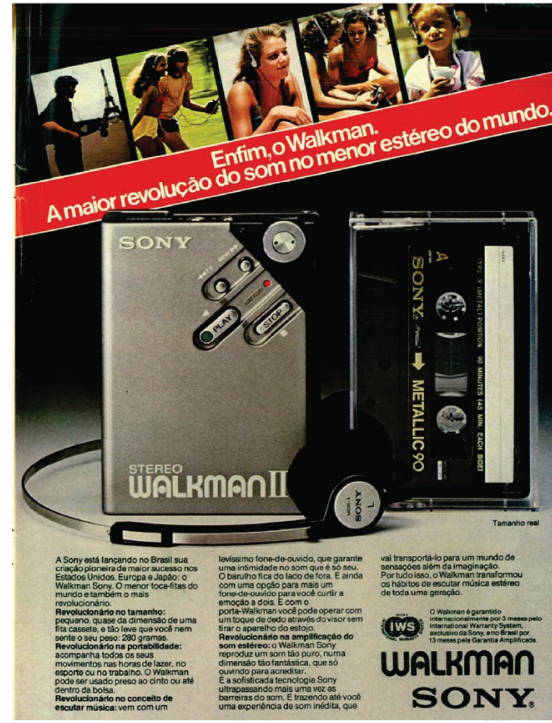

Walkman Sony - anúncio página simples veiculado na revista Veja, edição 718, de 9 jun. 1982, p. 163 Fonte: http://veja.abril.com.br/acervodigital/ home.aspx.

Em um segundo momento, diferentemente de 1982, cujas peças sugeriam a mobilidade em seu discurso, mas ainda não a usavam como argumento de vendas, em 1998 a cultura da mobilidade aparecia mais claramente no discurso das marcas: palavras como "movimento" e "globalização" são citadas nos textos e se somam às palavras que evocam mobilidade em potência, como "viagem", "liberdade", ou expressões como "volta ao mundo"; ou ainda verbos como "rodar", no sentido de circular, e "rolar", no sentido de acontecer. Tal alteração no discurso é resultado do contexto sócio-histórico global e, principalmente, nacional.

Conforme comentado, em 1998 o Brasil já se encontrava em outra situação social, política e econômica diante do mercado globalizado e fazia mais sentido, portanto, que questões culturais da sociedade móvel, em rede e de riscos fossem expressas com mais frequência no discurso publicitário. Inclusive termos como "tranquilidade" e "segurança" 
passaram a fazer parte também dos argumentos discursivos nos anúncios publicitários.

Nesta mesma época, a noção de mobilidade passa a ser utilizada como argumento de vendas, isto é, como um atributo do produto ou serviço que deve ser levado em conta pelo público-alvo ao tomar suas decisões de consumo. Desta forma, as marcas já começaram a considerar seus produtos ou serviços como objetos que poderiam potencializar (ou não) a propensão à (i)mobilidade do sujeito consumidor quando reforçavam em seu discurso a parceria entre o objeto e o indivíduo, como na peça do Nokia $6120^{13}$ ou da IBM ${ }^{14}$.

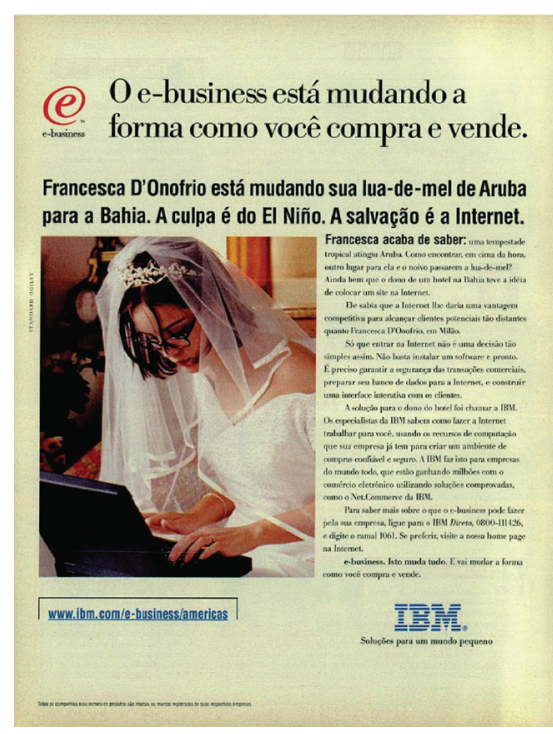

IBM - anúncio página simples veiculado na revista Veja, edição 1550, de 10 jun. 1998, p. 38.

Fonte: http://veja.abril.com.br/acervodigital/ home.aspx.

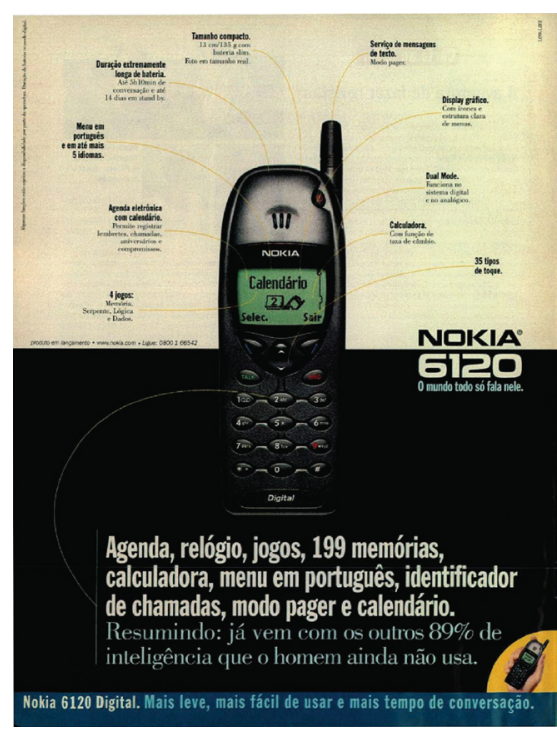

Nokia 6120 - anúncio página simples veiculado na revista Veja, edição 1550 , de 10 jun. 1998, p. 10.

Fonte: http://veja.abril.com.br/acervodigital/ home.aspx.

Neste sentido, já foi possível perceber a presença da noção de mooring, de Urry (2007), e de roots with wings, de Beck (2008), no discurso

13 Anúncio de página simples veiculado na revista Veja, edição 1550, de 10 jun. 1998, p. 10.

14 Anúncio de página simples veiculado na revista Veja, edição 1550, de 10 jun. 1998, p. 38. 
publicitário de marcas globais veiculado no Brasil. Os produtos ou serviços, enquanto objetos, já eram pensados no sentido de atender a uma demanda por potência de movimento do indivíduo, mesmo que este indivíduo estivesse fixo ou em deslocamento físico. A cultura da mobilidade e a individualização da vida social, política e econômica havia emergido com força no exterior e começado a despontar internamente a partir da participação do Brasil na economia neoliberal global. Certa "equalizada" nos contextos global e local foi determinante, também, para uma "equalizada” do discurso. Em 1998, algumas empresas globais já utilizavam a mesma campanha em diversos países, com pequenos ajustes, como, por exemplo, na tradução do texto para a língua local, ou nem mesmo isso.

Em 2014, o foco do discurso já é todo no indivíduo. Como vimos, o ambiente fluido, em rede e de riscos da contemporaneidade globalizada cria novas affordances e demanda novos produtos e ou serviços que estejam ready-to-hand para serem usados. Na tentativa de organizar a vida à distância e em constante movimento, o indivíduo busca por objetos que sustentem sua permanente (i)mobilidade. Cada dia mais, a parceria entre os objetos e a máquina empodera o sujeito ao oferecer o potencial de movimento necessário para a realização de seus projetos e estilos de vida. O melhor exemplo desta tecnologia é o telefone celular que, de 1998 para 2014, assumiu variadas funções na vida do consumidor, ao ponto de ser considerado como protético (URRY, 2007), como na peça da Samsung ${ }^{15}$, na qual o celular substitui o coração do consumidor.

Neste anúncio, a cultura da mobilidade se impõe no discurso, em especial no discurso não verbal da peça, não só pelo uso intrínseco do objeto para a mobilidade virtual ou imaginativa - pelo celular é possível ver TV, assistir aos jogos e torcer pelo Brasil -, como também pela clara associação da tecnologia com o indivíduo - híbridos -, fortalecendo a noção de potencial de movimento - motilidade - oferecido pelo objeto ao seu usuário.

15 Anúncio página dupla veiculado na revista Veja, edição 2378, de 18 jun. 2014, p. 46-47. 


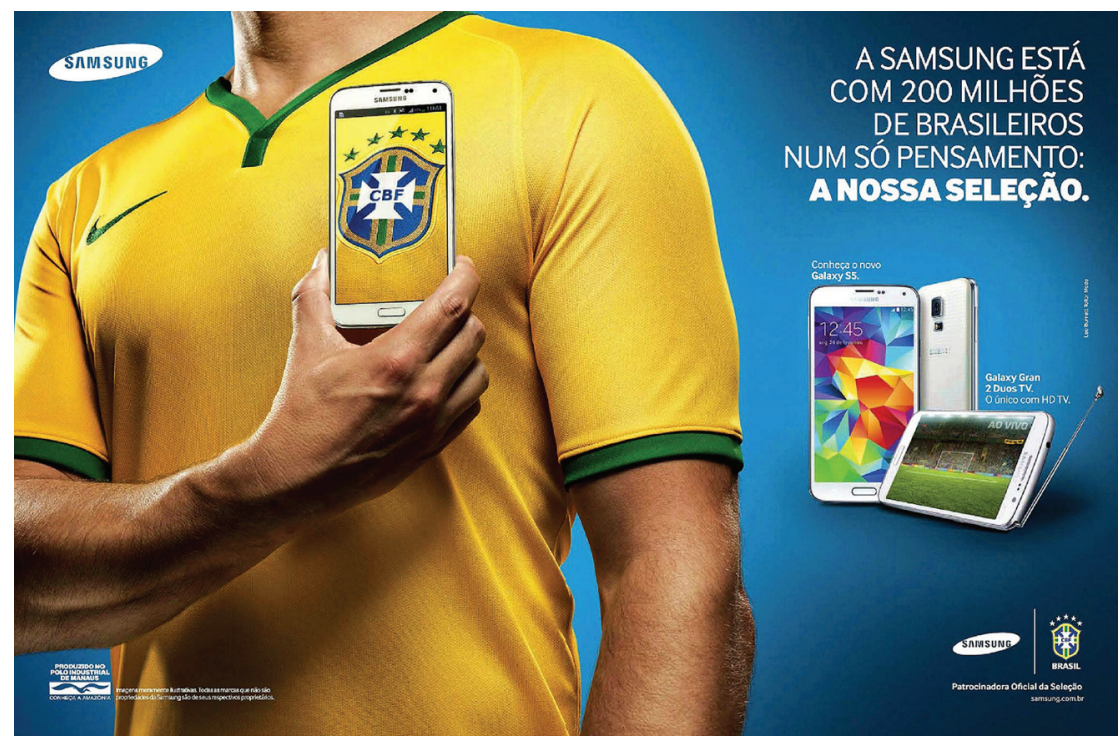

Samsung - anúncio página dupla veiculado na revista Veja, edição 2378, de 18 jun. 2014, p. 46-47.

Fonte: http://veja.abril.com.br/acervodigital/home.aspx.

Seguindo a mesma linha, o anúncio do site Brasil Post ${ }^{16}$ também fala do consumo individualizado de informação, no caso, jornalística, sempre através do celular, objeto símbolo da vida handy dos híbridos que, neste caso, podem ser encarados como os transumers ou consumidores em trânsito. A peça foi selecionada por ser a única, nas seis edições pesquisadas de 2014, que fazia alusão às Jornadas de Junho em seu texto.

No anúncio, uma foto de manifestantes é utilizada como imagem de fundo e, além disso, as manifestações de 2013 são o assunto das mensagens trocadas por usuários do Twitter retratadas no celular que compõe a imagem. A troca de informações real time, on line e on the move é o tema deste anúncio que tem no título o reforço do conceito da mobilidade/circulação da informação via meios digitais e de dispositivos móveis: "notícias geram conversas, conversas geram notícias". O Brasil Post, do grupo do The Huffington Post e associado à Editora Abril, assina

${ }^{16}$ Anúncio página simples veiculado na revista Veja, edição 2378, de 18 jun. 2014, p. 93. 
a peça afirmando que "o futuro do jornalismo chegou [...] no seu tablet, smartphone e nas redes sociais".

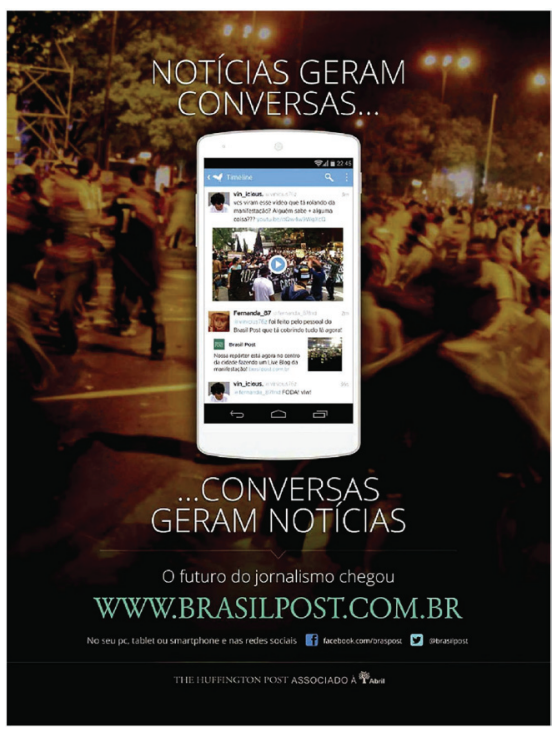

BrasilPost - anúncio página simples veiculado na revista Veja, edição 2378, de 18 jun. 2014, p. 93.

Fonte: http://veja.abril.com.br/acervodigital/home.aspx.

Conforme ressaltou Urry (2007), na contemporaneidade, a partir da parceria entre homem e máquina, a vida social, de trabalho ou em família, a educação e a atuação política, como é o caso nesta peça, podem ser experimentadas à distância ou mesmo durante o deslocamento, o que determina novas possibilidades de vida e de fruição do sujeito com seus grupos sociais e seus objetos de consumo. Neste sentido, a cultura da mobilidade está presente no anúncio não só discursivamente, mas também pela maneira como há o consumo e o uso da informação na organização da vida à distância oferecida pelo próprio objeto e meio de divulgação, a internet.

Desta forma, de 1982 a 2014, a argumentação discursiva dos anúncios migrou da tecnologia da máquina, expressa, por exemplo, no anúncio do Monza, de 1982, para o acesso à internet e às redes sociais, como 
visto na peça da Mitsubishi ${ }^{17}$, de 2014; migrou da técnica aplicada à mobilidade física e/ou geográfica, como na portabilidade revolucionária do walkman, de 1982, para a técnica aplicada à mobilidade virtual ou imaginativa, como na peça da $\mathrm{TIM}^{18}$, de 2014; migrou da tecnologia dos "grandes" sistemas, como no anúncio do Itaú Eletrônica Global, de 1982, para o projeto e estilo de vida do indivíduo e sua vida handy, como no caso do já citado anúncio do Brasil Post ${ }^{19}$, de 2014.

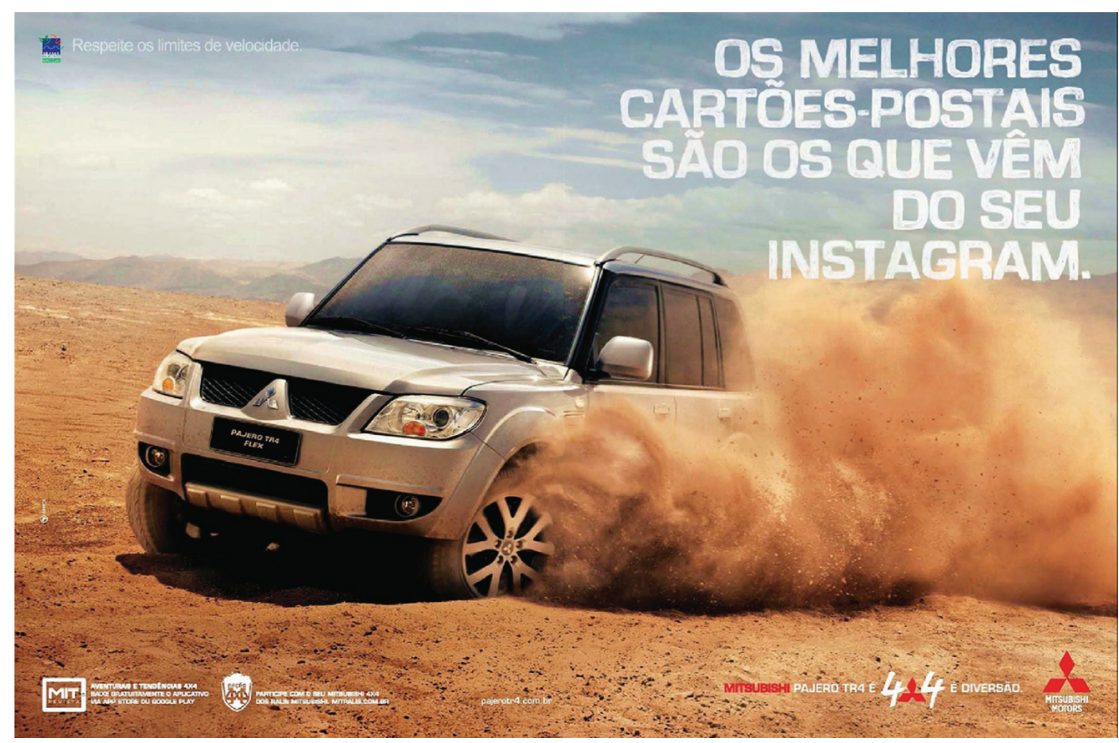

Mitsubishi - anúncio página dupla veiculado na revista Veja, edição 2382, de 16 jul. 2014, p. 20-21.

Fonte: http://veja.abril.com.br/acervodigital/home.aspx.

17 Anúncio de página dupla veiculado na revista Veja, edição 2382, de 16 jul. 2014, p. 20-21.

18 Anúncio de página dupla veiculado na revista Veja, edição 2379, de 25 jun. 2014, p. 2-3.

19 Anúncio página simples veiculado na revista Veja, edição 2378, de 18 jun. 2014, p. 93. 


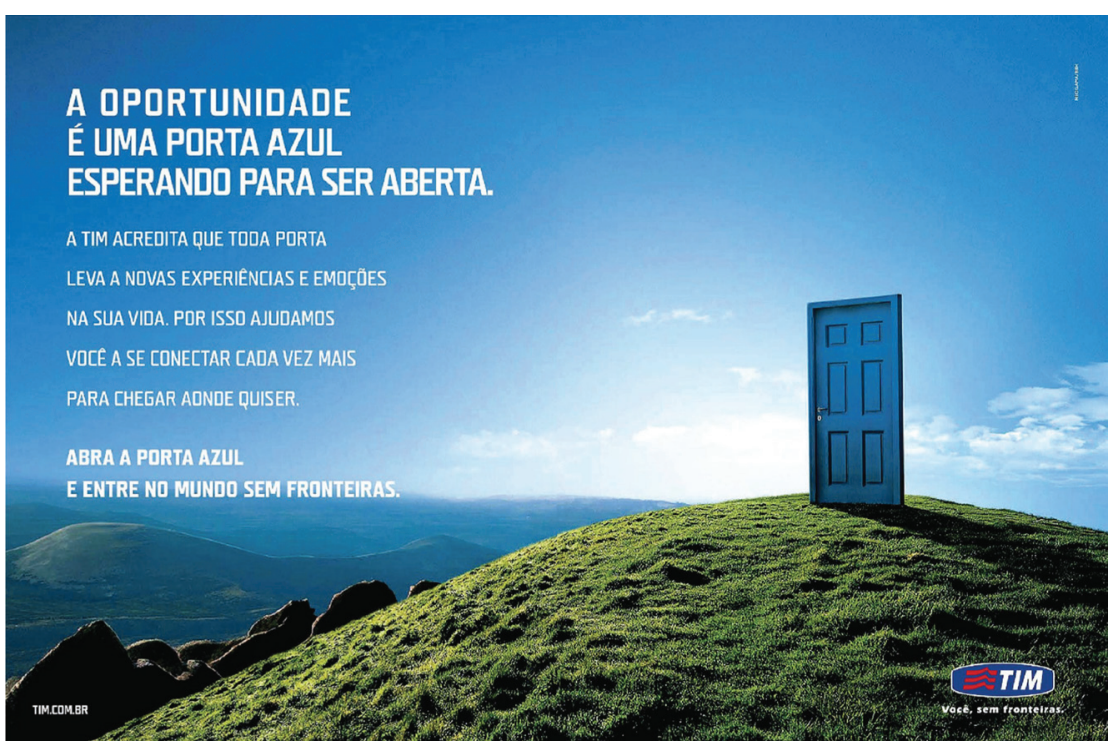

TIM - anúncio página dupla veiculado na revista Veja, edição 2379, de 25 jun. 2014, p. 2-3.

Fonte: http://veja.abril.com.br/acervodigital/home.aspx. => imagem pág 45

\section{Considerações finais}

A diversidade de marcas, de produtos ou de serviços que utilizam a mobilidade em potência como argumento discursivo remete à questão do acesso, da habilidade e da apropriação da potência pelo indivíduo. Como afirmam Kaufmann e Montulet (2008), a mobilidade é prática que se realiza no interior de uma dimensão pessoal, na qual o ritmo de vida (estilos e projetos) e as condições espaço-temporais do indivíduo é que são relevantes. Ao se tratar da publicidade, pode-se fazer uma crítica de que nem todos os produtos estão disponíveis para todos os públicos. De fato, uma das primeiras questões do fazer publicitário é saber para quem àquela comunicação será dirigida, isto é, qual será seu público-alvo. Neste sentido, para cada objetivo, estilo e projeto, há um produto ou serviço dirigido àquele público. Os possíveis constrangimentos de acesso ou de habilidade de apropriação da motilidade comercializada 
pela comunicação publicitária das marcas não estariam, portanto, na veiculação da publicidade em si. O problema estaria nas desigualdades no acesso e na possibilidade de apropriação da infraestrutura de transporte e de comunicação necessárias para a transformação da potência em movimento real, se necessário. Inclusive, para alguns autores, no caso do Brasil, esta desigualdade teria sido um dos motivos das manifestações de junho de 2013.

E para finalizar, ao confirmar a hipótese de que a cultura da mobilidade está presente no discurso da comunicação publicitária de marcas globais veiculada no Brasil desde, pelo menos, 1982, a tese fortaleceu a premissa de que a publicidade pode ser encarada, ela mesma, como um produto cultural, que vale ser estudado como tantas outras formas simbólicas e manifestações culturais da sociedade moderno-contemporânea. A riqueza de conteúdo que há por trás do caráter persuasivo e de convencimento da publicidade permite ao pesquisador um interessante mergulho sócio-histórico e a posiciona como um válido meio de compreensão dos tempos modernos. Mas para pensar a publicidade como memória e patrimônio é preciso suspender os preconceitos, como afirmam Simmel (2011) e Gadamer (1999), e não limitar a publicidade ao papel de vilã do capitalismo global, entendendo-la como parte de um processo maior que envolve quem vende, mas também quem compra, em diversas e novas (re)configurações, dentre as quais a mobilidade em potência.

\section{Referências}

APPADURAI, A. The social life of things: commodities in cultural perspective. Reino Unido: Cambridge University Press, 1986. Kindle Edition para iPad.

BAUDRILLARD, J. A Sociedade de Consumo. Lisboa: Edições 70, 1970. 247 p. BECK, U. Mobility and the cosmopolitan perspective. In: WEERT, C.; KAUFMANN, V.; KESSELRING, S. (Eds.). Trancing mobilities: towards a cosmopolitan perspective. Reino Unido: Ashgate, 2008. p. 25-36. 
GADAMER, H-G. Verdade e Método: traços fundamentais de uma hermenêutica filosófica. Petrópolis: Vozes, 1999. (1. ed. 1948).

HALL, S. A identidade cultural na pós-modernidade. Rio de Janeiro: DP\&A, 2003. 102 p. KAUFMANN, V. Re-thinking mobility. Contemporany sociology. Reino Unido: Ashgate, 2002. $112 \mathrm{p}$.

KAUFMANN, V.; MONTULET, B. Between social and spatial mobilities: the issue of social fluidity. In: WEERT, C.; KAUFMANN, V.; KESSELRING, S. (Eds.). Tracing mobilities: towards a cosmopolitan perspective. Reino Unido: Ashgate, 2008. p. 37-55. KESSELRING, Sven. Mobility risk society. In: WEERT, C.; KAUFMANN, V.; KESSELRING, S. (Eds.). Tracing mobilities: towards a cosmopolitan perspective. Reino Unido: Ashgate, 2008. p. 77-102.

MAIA, J. M.; ROCHA, L. Protests, protests, everywhere. Will the "Iune Journeys" Spoil Brazil's bid for Glory? Cairo Review, n. 12, p. 79-85, 2014.

MCCRACKEN, G. Cultura E consumo. Rio de Janeiro: Mauad, 2003. 206 p.

MCCRACKEN, G. Consumo e Cultura II: mercados, significados e gestão de marcas. Rio de Janeiro: Mauad, 2012. 304 p.

MILLER, D. Trecos, troços e coisas: estudos antropológicos sobre a cultura material. Rio de Janeiro: Zahar, 2013. Kindle Edition para iPad.

NERI, M. C. (Coord.). A nova classe média: o lado brilhante dos pobres. Rio de Janeiro: FGV/CPS, 2010. Disponível em: http://www.cps.fgv.br/cps/ncm/. Acesso em: 1 abr. 2016.

NERI, M. C. De Volta ao País do Futuro: Crise Europeia, Projeções e a Nova Classe Média. Rio de Janeiro: FGV/CPS, 2012. Disponível em: http://www.cps.fgv.br/cps/ ncm2014/.

NOGUEIRA, M. A. de F. Consumo e Publicidade: apropriação localizada e mensagem global. Dissertação de Mestrado em Comunicação Social. PUC-Rio. Março de 2010. 112p. Disponível em: http://www.maxwell.vrac.puc-rio.br/16030/16030_1.PDF.

Mobilidade em potência e discurso publicitário na sociedade contemporânea globalizada. Tese de Doutorado em História, Política e Bens Culturais. Centro de Documentação da História Contemporânea do Brasil, FGV-RJ. Março, 2015. 329p. Disponível em: http://hdl.handle.net/10438/13704.

ORTIZ, R. Mundialização e cultura. Rio de Janeiro: Brasiliense, 2003. 235 p.

ROCHA, E. P. G. Magia e Capitalismo: um estudo antropológico da publicidade. 3. ed. São Paulo: Brasiliense, 1985. 162 p.

SIMMEL, G. Ensaios sobre a teoria da história. Rio de Janeiro: Contraponto, 2011. 107 p. THOMPSON, J. B. Ideologia e cultura moderna: teoria social crítica na era dos meios de comunicação de massa. Petrópolis: Vozes, 2000. 427 p.

VISENTINI, P. F. A projeção internacional do Brasil. 1930-2012. São Paulo: Elsevier, 2013. $151 \mathrm{p}$.

URRY, J. Mobile Cultures. Reino Unido: Lancaster University, Department of Sociology, 2003. (1. ed. 1999). Disponível em: http://www.lancaster.ac.uk/fass/resources/sociology-online-papers/papers/urry-mobile-cultures.pdf. Acesso em: 1 abr. 2016.

URRY, J. Mobilities. Cambridge, Reino Unido: Polity Press, 2007. 325 p. 


\section{Meios eletrônicos}

http:/hdl.handle.net/10438/13704.

http://veja.abril.com.br/acervodigital/home.aspx.

http://veja.abril.com.br/especiais/veja_40anos/p_170.html. Acessado em: 19 jan. 2015.

http://agenciabrasil.ebc.com.br/economia/noticia/2014-10/

inflacao-acumulada-em-12-meses-e-maior-em-tres-anos.

http://www.ihu.unisinos.br/entrevistas/521 147-a-busca-por-reconhecimento-e-participacao-politica-o-combustivel-das-manifestacoes-entrevista-especial-com-werneck-vianna-. http://esportes.estadao.com.br/noticias/futebol,protestos-arruinam-imagem-do-brasil-e-preocupam-a-fifa, 1045721.

\section{Sobre a autora}

Maria Alice de Faria Nogueira - Doutora em História, Políticas e Bens Culturais, Cpdoc/FGV-RJ; Professora de Comunicação e Marketing na Escola de Comunicação - ECO/UFRJ; Professora e Pesquisadora na Universidade Estácio de Sá - UNESA.

Data de submissão: 30/08/2015

Data de aceite: 23/10/2015 